\title{
Input and Output Indicators of Higher Education Institutions for Quality of Life in Portugal
}

\author{
Ana Luísa Rodrigues ${ }^{1}$, Luísa Cerdeira ${ }^{1}$, Tomás Patrocínio ${ }^{1}$, Belmiro Cabrito ${ }^{1} \&$ Pedro Mucharreira $^{1}$ \\ ${ }^{1}$ Institute of Education, University of Lisbon, Portugal \\ Correspondence: Ana Luísa Rodrigues, Instituto de Educação, Universidade de Lisboa, Alameda da Universidade \\ 1649-013 Lisboa, Portugal.
}

Received: October 27, 2020

Accepted: January 6, 2021

Online Published: January 6, 2021

doi:10.5430/ijhe.v10n2p299

URL: https://doi.org/10.5430/ijhe.v10n2p299

\begin{abstract}
Higher education institutions (HEIs) contribute substantially to the quality of life (QoL) of the regions where they operate and to the progress and sustainable development of a country. This research intends to have an innovative approach in the study of the HEIs' impact on the QoL of regions by taking into consideration both qualitative and quantitative indicators. This study aims to identify, collect and systematize indicators that can be used to measure the impact of HEIs on QoL: on the demand-side based on expenditure (inputs) and the knowledge-based supply side (outputs). For accomplishing this, the authors carried out a literature review, an analysis of available statistical data in Portugal and interviews for the analysis and consolidation of indicators. The results will facilitate the measurement of the HEIs' impact on QoL and regions and allow the elaboration of a matrix of reliable indicators, which will hopefully assist in the definition of new higher education policies.
\end{abstract}

Keywords: indicators, R\&D, higher education institutions, quality of life, education policies

\section{Introduction}

In the Bologna Process, improving the quality and relevance of teaching and learning in higher education has always been a central issue (European Commission /EACEA/Eurydice, 2018). Regardless of national policies, it is assumed that most higher education institutions (HEIs) have contributed to the quality of life $(\mathrm{QoL})$ in the surrounding regions.

At the same time, these institutions play a relevant role in economic and social growth and development, particularly in terms of improving human capital (Pedro, Leitão, \& Alves, 2018) and research and development (R\&D), with consequences for the population's QoL and in society at large.

In Portugal, Leitão, Alves and Pereira (2016) have developed several studies on this topic, namely on the effects of open innovative governance and municipalities' transparency on citizens' QoL. To assess the effects on QoL, the positive variation in the citizens'purchasing power index was taken into account. In this study, the main results revealed a significant influence of open innovative governance on citizens' QoL regarding two dimensions: plans and planning; and taxes, fees, prices and regulations. Furthermore, the results reveal a positive association between HEIs and QoL, although it can be mitigated by the negative effects associated with low population density and variation in the purchasing power.

In another study on an innovative operational proposal for measuring the intellectual capital of higher education institutions, Pedro, Leitão and Alves (2019) concluded that human capital, structural capital and relational capital make up the core components and provide a fairly diversified list of the measurement indicators for the operational evaluation of the intellectual capital of HEIs.

According to a study by Winters (2011) in the United States of America, QoL can be positively affected, either by the level of human capital or by the relative importance of HEIs, measured respectively by higher education graduates and students enrolled in higher education. These effects are accentuated when these variables are considered simultaneously, and they are strongly correlated.

On the other hand, HEIs as institutions, whose diversity of activities generates a substantial amount of expenses, also contribute to the local economy (Kelly, McNicoll, \& McLellan, 2006). However, their importance goes beyond this economic activity as they influence the social and cultural environment in various ways, which, in turn, will also affect the economic environment (Kelly et al., 2006; Pedro et al., 2018). In addition, Drucker (2016) states that the level of 
human capital and the presence of HEIs have a shared effect and also separate effects on the populations QoL, as also reported in another study in Portugal (Pedro et al., 2018).

The present study is part of the U-Value Research Project funded by the Foundation for Science and Technology. This research project aims to develop: i) a system of indicators that can be used to quantify the influence of HEIs on the QoL of populations in their regions; ii) a multidimensional impact matrix of HEIs on the QoL of the populations of their regions; and iii) a system for monitoring and quantifying the QoL of the population in the region of influence of each HEI.

This paper is a preliminary study that aims to identify and analyze some statistical-based indicators in Portugal, on the demand-side basis (inputs), at the population, student and R\&D levels; and the knowledge-based supply side (outputs), related to human capital, innovation and knowledge transfer, as a way to identify and consolidate information on indicators that can contribute to the QoL of the surrounding regions.

Pedro, Leitão, and Alves (2020) confirm that intellectual capital directly and positively influences sustainable development practices and that these strongly influence the students' quality of life, although the same is not true for teachers and researchers. These insights are important for policy-making and intellectual capital management in HEIs, as they show that: the sustainable development concept is associated with HEIs' economic, environmental, social and organizational practices; HEIs need to improve the social dimension of their sustainable development practices; the inclusion of the best sustainable practices has an impact on the quality of life of all stakeholders.

\section{Method}

The Method section describes in detail how the study was conducted, including conceptual and operational definitions of the variables used in the study. Different types of studies rely on different methodologies; however, a complete description of the methods used enables the reader to evaluate the appropriateness of the methods and the reliability and validity of the results. It also permits experienced investigators to replicate the study. If the manuscript is an update of an ongoing or earlier study and the method has been published in detail elsewhere, the author(s) may refer the reader to that source and simply give a brief synopsis of the method in this section.

This work, inserted in the U-Value research project, aims to identify and collect data on some of the HEIs' indicators, inputs and outputs that may have an impact on the life of the population of the institution's region of influence.

Taking into account the literature review, and after the construction of the model, the selection and definition of key indicators was performed. These were validated with various stakeholders, such as entities from the academic, political and social context, economic agents, students, alumni and residents of the HEIs' location areas in Portugal, through interviews and statistical analysis.

This article looks at some of these demand-side indicators based on expenditure (inputs): population with higher education qualifications, number of students enrolled in higher education, expenditure and staff in R\&D activities; and knowledge-based supply side (outputs): graduates and employed population with higher education, GDP (Gross Domestic Product) and labour productivity, and technological innovation and knowledge transfer.

To quantify the indicators to be analysed, Portuguese public databases were used, such as the Contemporary Portugal Database (Note 1) and the National Institute of Statistics (Note 2). Several national and international statistics reports were also used.

\section{Results}

Based on the secondary data collected in the databases, in order to sustain and infer relationships between the role of HEIs and enterprises, focusing on human capital, innovation and knowledge transfer, the following indicators were analysed in Portugal, at the level of inputs: (i) population with higher education qualifications, number of students enrolled in tertiary education by subsystem, type of education and of education; (ii) staff and expenditure in R\&D activities; and based on outputs: iii) graduates and employed population with higher education qualifications; iv) number of enterprises, GDP and apparent labour productivity; v) enterprises with technological innovation activities and patents of registered inventions.

\subsection{Input Indicators}

Portugal has a total resident population of around 10 million people, with a tendency for a slow decrease. The active population is about $50 \%$ of the total population.

Nevertheless, although it can be said that, globally, the "School" has become massified, both in terms of who attends and the length of stay, there are still many Portuguese citizens who do not have any level of complete education. In 
1960, two-thirds of resident individuals did not have any educational level and, in 1981, 22\% of the population was still in this situation. In 2012, there were half a million illiterate individuals, according to the latest Census (Note 3 ).

Table 1. Population with higher education

\begin{tabular}{|r|r|r|r|r|r|r|r|}
\hline \multicolumn{2}{|c|}{ Resident population in Portugal (In thousands) } & \multicolumn{3}{c|}{ \% With higher education (Portuguese and UE28) } \\
\hline \multicolumn{1}{|c|}{$\mathbf{2 0 0 1}$} & $\mathbf{2 0 1 0}$ & $\mathbf{2 0 1 4}$ & $\mathbf{2 0 1 9}$ & $\mathbf{2 0 0 1}$ & $\mathbf{2 0 1 0}$ & \multicolumn{1}{c|}{$\mathbf{2 0 1 4}$} & $\mathbf{2 0 1 9}$ \\
\hline 10363 & 10573 & 10401 & 10286 & $9 \%$ & $16 \%$ & $22 \%$ & $26 \%$ \\
\hline- & $2 \%$ & $-2 \%$ & $-1 \%$ & UE28 & $\mathbf{2 6 \%}$ & $\mathbf{2 9 \%}$ & $\mathbf{3 3 \%}$ \\
\hline
\end{tabular}

Source: INE | PORDATA (last update: June 2020)

The evolution of the population between 25 and 64 years old, with higher education qualifications (ISCED 5-8), has been quite positive since 2001 , with $26 \%$ holding higher education qualifications in 2019 , compared to 2001 , when there were only 9\% (Table 1). However, these percentages are still below the European average (Note 4), which, in 2019, was 33\%.

Table 2. Students enrolled in higher education by education subsystem and type of education

\begin{tabular}{|c|c|c|c|c|c|c|c|}
\hline \multicolumn{4}{|c|}{ Students in higher education } & \multicolumn{4}{|c|}{ By education subsystem and type of education } \\
\hline \multicolumn{4}{|c|}{ Total (Persons) } & Public & Private & College & Polytechnic \\
\hline 2001 & 2010 & 2014 & 2019 & \multicolumn{4}{|c|}{2019} \\
\hline 387703 & 383627 & 362200 & 385247 & 316189 & 69058 & 247867 & 137380 \\
\hline- & $-1 \%$ & $-6 \%$ & $6 \%$ & $82 \%$ & $18 \%$ & $64 \%$ & $36 \%$ \\
\hline
\end{tabular}

Source: DGEEC/MEd - MCTES| PORDATA (last update: September 2020)

Regarding the number of students enrolled in higher education, according to Table 2 , there is a decrease of $1 \%$ from 2001 to 2010 and $6 \%$ from 2010 to 2014 . There was a recovery of growth of $6 \%$ in 2019 , even with the influence of the decline in birth rates in the last two decades.

In 2019 , the vast majority, $82 \%$ of students, were enrolled in public education, and university education dominates, with $64 \%$ of students enrolled, compared to $36 \%$ of polytechnic education.

Table 3. Students enrolled in higher education by educational level

\begin{tabular}{|c|r|r|r|r|r|r|r|}
\hline \multicolumn{7}{|c|}{ Students in Higher Education by educational level } \\
\hline $\mathbf{2 0 1 9}$ & $\begin{array}{c}\text { Total } \\
\text { (Persons) }\end{array}$ & Graduation & $\begin{array}{c}\text { Integrated } \\
\text { Master }\end{array}$ & Master & PhD & $\begin{array}{c}\text { Professio- } \\
\text { nal Higher } \\
\text { Technical }\end{array}$ & $\begin{array}{c}\text { Speciali- } \\
\text { zation }\end{array}$ \\
\hline Total & 385247 & 219615 & 62854 & 62976 & 21090 & 15423 & 3289 \\
\hline$\%$ & $\mathbf{1 0 0 \%}$ & $\mathbf{5 7 \%}$ & $\mathbf{1 6 \%}$ & $\mathbf{1 6 \%}$ & $\mathbf{5 \%}$ & $\mathbf{4 \%}$ & $\mathbf{1 \%}$ \\
\hline
\end{tabular}

Source: DGEEC/MEd - MCTES| PORDATA (last update: September 2020)

Concerning students enrolled in higher education by level of education, in $2019,57 \%$ of the higher education students were attending a Graduation and 16\% a Master Degree program, while 16\% were in Integrated Master Programs. Only $5 \%$ were enrolled in Doctoral programs and 1\% of students in Specialization programs. It is noteworthy that $4 \%$ of the students were enrolled in the Higher Professional Technician (TESP) programs, which underwent a major legislative update in 2016 (Table 3).

Also, as indicators at the level of inputs, we analyzed the work force and expenses in R\&D activities.

Table 4. Staff in R\&D by implementation sectors

\begin{tabular}{|c|c|c|c|c|c|c|c|}
\hline \multicolumn{4}{|c|}{ Staff in R\&D } & \multicolumn{4}{|c|}{ By implementation sectors } \\
\hline \multicolumn{4}{|c|}{ Total (Persons) } & Enterprises & State & Higher & $\begin{array}{l}\text { Nonprofit } \\
\text { Private }\end{array}$ \\
\hline 2001 & 2010 & 2014 & 2018 & \multicolumn{4}{|c|}{2018} \\
\hline 22970 & 47616 & 46878 & 58154 & 23662 & 2283 & 31451 & 759 \\
\hline - & $52 \%$ & $-2 \%$ & $19 \%$ & $41 \%$ & $4 \%$ & $54 \%$ & $1 \%$ \\
\hline
\end{tabular}

Source: DGEEC/MEd - MCTES| PORDATA (last update: January 2020) 
"Staff in R\&D Activities" means all staff directly connected with R\&D activities, such as researchers and those providing services directly linked to R\&D activities. This includes the creative work systematically pursued with a view to broadening the body of knowledge, including knowledge of man, culture and society, as well as the use of this body of knowledge in new applications . $^{\mathrm{i}}$.

As a result, there has been a significant increase over the past few years of R\&D staff, more than doubling from 2001 to 2017. It was also found that, in 2017, the majority of R\&D staff (54\%) were placed in Higher Education, followed by Enterprises (41\%). Only 4\% of R\&D staff were placed in the State and 1\% in Non-profit private institutions (Table 4).

Table 5. Expenditure in R\&D by implementation sectors

\begin{tabular}{|c|c|c|c|c|c|c|c|}
\hline \multicolumn{4}{|c|}{ Expenditure in R\&D } & \multicolumn{4}{|c|}{ By implementation sectors } \\
\hline \multicolumn{4}{|c|}{ Total (in thousands EUR) } & Enterprises & State & $\begin{array}{l}\text { Higher } \\
\text { Education }\end{array}$ & $\begin{array}{l}\text { Nonprofit } \\
\text { Private } \\
\text { Institutions }\end{array}$ \\
\hline 2001 & 2010 & 2014 & 2018 & \multicolumn{4}{|c|}{2018} \\
\hline 1038432 & 2757555 & 2232249 & 2769072 & 1424578 & 147038 & 1152721 & 44736 \\
\hline- & $62 \%$ & $-24 \%$ & $19 \%$ & $51 \%$ & $5 \%$ & $42 \%$ & $2 \%$ \\
\hline
\end{tabular}

Source: DGEEC/MEd - MCTES| PORDATA (last update: January 2020)

According to Table 5, as for R\&D Expenses, there was a decrease from 2010 to 2014 but then an increase from 2014 to 2018. The Enterprises accounted for the highest percentage of expenses, representing $51 \%$ of the amounts invested, followed by Higher education representing $42 \%$ of the expenditure on R\&D activities in 2018.

\subsection{Output indicators}

From the indicators based on the outputs we analyzed the number of graduates (Table 6) and the population employed with higher education qualifications (Table 7).

Table 6. Higher education graduates by educational level

\begin{tabular}{|c|c|c|c|c|c|c|c|}
\hline \multicolumn{4}{|c|}{ Higher education graduates } & \multicolumn{4}{|c|}{ By educational level } \\
\hline \multicolumn{4}{|c|}{ Total (Persons) } & Graduation & $\begin{array}{c}\text { Integrated } \\
\text { Master }\end{array}$ & Master & PhD \\
\hline 2001 & 2010 & 2014 & 2019 & \multicolumn{4}{|c|}{2019} \\
\hline 61140 & 78609 & 75906 & 83193 & 49085 & 8279 & 17490 & 2103 \\
\hline - & $22 \%$ & $-4 \%$ & $9 \%$ & $59 \%$ & $10 \%$ & $21 \%$ & $3 \%$ \\
\hline
\end{tabular}

Source: INE | PORDATA (last update: July 2020)

For Higher education graduates, there was a substantial increase of $22 \%$ from 2001 to 2010 , followed by a slight decrease from 2010 to 2014, in line with the decrease in the number of students enrolled. The distribution by level of education is diverse, with 59\% of Graduates, 10\% holding an Integrated Master's, 21\% holding a Master's, and 3\% holding a PhD in 2019 (Table 6).

Table 7. Employed population with tertiary education as a level of education

\begin{tabular}{|r|r|r|r|r|r|r|r|}
\hline \multicolumn{2}{|c|}{ Employed population } & \multicolumn{4}{c|}{ (Persons in thousands) } & & \multicolumn{3}{c|}{ With tertiary education } \\
\hline \multicolumn{1}{|c|}{} & $\mathbf{2 0 1 0}$ & $\mathbf{2 0 1 4}$ & $\mathbf{2 0 1 9}$ & $\mathbf{2 0 0 1}$ & $\mathbf{2 0 1 0}$ & $\mathbf{2 0 1 4}$ & $\mathbf{2 0 1 9}$ \\
\hline 5128 & 4898 & 4500 & 4913 & 498 & 820 & 1076 & 1374 \\
\hline- & $\mathbf{- 5 \%}$ & $\mathbf{- 9 \%}$ & $\mathbf{8 \%}$ & $\mathbf{1 0 \%}$ & $\mathbf{1 7 \%}$ & $\mathbf{2 4 \%}$ & $\mathbf{2 8 \%}$ \\
\hline
\end{tabular}

Source: INE | PORDATA (last update: February 2020)

The Employed population declined from 2001 to 2010 and to 2014, as a result of the increase in the unemployment rate in Portugal since 2000 (which stood at 3.9\%), which only started to reverse in 2014 (from 16.2\% in 2013 to $13.9 \%$ in 2014) (Note 2). However, comparing the total of employees with the employed population with a higher education level, there is a substantial increase, almost doubling from 2001 to 2010 , from $10 \%$ to $17 \%$, and also a significant increase from 2010 to 2019 , being, in 2019, $28 \%$ of employees with higher education compared to the total population (Table 7). It may also be added that the work force in knowledge-intensive high-tech services in 2017 represents only $2 \%$ of the total Employed population, with 97,437 employees (Note 2). 
Table 8. Total number of enterprises, GDP and Apparent labour productivity

\begin{tabular}{|c|c|c|c|c|c|c|c|}
\hline 2001 & 2010 & 2014 & 2018 & 2001 & 2010 & 2014 & 2018 \\
\hline \multicolumn{4}{|c|}{ Number of entreprises } & \multicolumn{4}{|c|}{ Portuguese GDP per capita (PPS) } \\
\hline 593574 & 1168265 & 1147154 & 1295299 & 16164 & 20636 & 20593 & 23359 \\
\hline- & $97 \%$ & $-2 \%$ & $13 \%$ & - & $28 \%$ & $\mathbf{0 \%}$ & $13 \%$ \\
\hline \multicolumn{4}{|c|}{ Apparent labour productivity (In thousands EUR) } & \multicolumn{4}{|c|}{ UE28 GDP per capita (PPS) } \\
\hline 24183 & 34012 & 35589 & 37595 & 19651 & 25256 & 26961 & 30443 \\
\hline - & $41 \%$ & $5 \%$ & $6 \%$ & - & $29 \%$ & $7 \%$ & $13 \%$ \\
\hline
\end{tabular}

Source: INE and Eurostat | PORDATA (last update: September 2020)

The data in Table 8 shows that there is an increase in the number of enterprises with strong growth between 2001 and 2010, decreasing until 2014. From 2014 to 2018, enterprises have a 13\% growth. As for the apparent labour productivity of enterprises, there is a growth of $41 \%$ until 2010 , a decrease of $5 \%$ from 2010 to 2014 , but reversing from 2014 to 2018, with a $6 \%$ growth rate.

Regarding GDP per capita (PPT), Portugal had a growth of 28\% between 2001 and 2010, remained steady from 2010 to 2014, and had an increase from 2014 to 2018, with a total growth rate of 13\%, similar to the growth in the EU28iv in the last period considered, but still below average (Table 8).

Table 9. Enterprises with technological innovation activities, by size and source of financing (\%)

\begin{tabular}{|ccccc|crr|}
\hline \multicolumn{2}{|c|}{ Enterprises with innovation activities (\%) By size } & & \multicolumn{3}{c|}{ By source of financing } \\
Total (\%) & $\begin{array}{c}\mathbf{1 0}-\mathbf{4 9} \\
\text { people }\end{array}$ & $\begin{array}{c}\mathbf{5 0}-\mathbf{2 4 9} \\
\text { people }\end{array}$ & $\begin{array}{c}\mathbf{2 5 0} \text { and } \\
\text { more people }\end{array}$ & $\begin{array}{c}\text { Local or } \\
\text { regional } \\
\text { administrat }\end{array}$ & $\begin{array}{c}\text { Central } \\
\text { administrat } \\
\text { ion }\end{array}$ & $\begin{array}{c}\text { European } \\
\text { Union }\end{array}$ \\
\hline Years & \multicolumn{3}{|c|}{$\mathbf{2 0 1 6 - 2 0 1 8}$} & & & $2016-2018$ & \\
\hline 32.4 & 29.2 & 46.5 & 61.5 & 2.1 & 2.9 & 6.5 \\
\hline
\end{tabular}

Source: INE (accessed October 2020)

Finally, the indicators related to technological innovation (Table 9) in the period between 2016 and 2018, and patents for inventions registered (Table 10) in the years 2014, 2016 and 2018, were analysed.

Enterprises are divided into Small and Medium-sized Enterprises (SMEs) - those employing less than 250 people and whose annual turnover does not exceed EUR 50 million or whose total annual balance sheet does not exceed EUR 43 million - and Large Enterprises (with more than 250 employees). To note that, in Portugal, 99.9\% of the enterprises are SMEs ${ }^{\text {ii }}$.

The analysis of Table 9 allows asserting that about $32.4 \%$ of all Enterprises have technological innovation activities, especially those that employ between 50 and 249 people, and substantially higher in Large Enterprises (with more than 250 employees), which represent $61.5 \%$ at the national level. In terms of the public funding source, in the same period (2016-2018), it is found that the European Union (EU) is the main funder of this investment (Table 9).

Table 10. Patent of inventions registered by type of applicant

\begin{tabular}{|c|c|c|c|c|c|c|}
\hline \multicolumn{3}{|c|}{ Patent of inventions registered } & \multicolumn{4}{|c|}{ By type of applicant } \\
\hline \multicolumn{3}{|c|}{ Total (N. $\left.{ }^{\circ}\right)$} & Enterprises & Universities & $\begin{array}{c}\text { Research } \\
\text { Institutions }\end{array}$ & $\begin{array}{l}\text { Independent } \\
\text { Inventors }\end{array}$ \\
\hline 2014 & 2016 & 2018 & \multicolumn{4}{|c|}{2018} \\
\hline 812 & 812 & 727 & 234 & 124 & 40 & 329 \\
\hline - & $0 \%$ & $-10 \%$ & $32 \%$ & $17 \%$ & $6 \%$ & $45 \%$ \\
\hline
\end{tabular}

Source: INE (accessed October 2020)

Regarding Patents for registered inventions (Table 10), they remain constant between 2014 and 2016, but there is a decrease of $10 \%$ from 2016 to 2018.

Considering the type of applicant, the Independent inventors and the Enterprises are the main contributors to patent registration. 


\subsection{Further Indicators Identified}

Many other indicators can be considered for the analysis of the complexity of the theme, taking into account that the competitive capacity of the region may be associated with the level of well-being of residents in a region (Leitão, Ferreira, \& Azevedo, 2008). In this way, HEIs can create sources of competitive advantage based on the elements of a technology-based economy, as identified by Berglund and Clarke (2000): the intellectual infrastructure that generates new ideas; knowledge transfer; advanced physical and technological infrastructures; the technically qualified workforce; capital related to information flows appropriate to investment sources; an entrepreneurial culture; and QoL that results from improvements in the infrastructure created around the HEI and that make the region more competitive.

Thus, at the level of inputs, it is important to consider ratios and indicators of HEIs' Economic Base (Own income), expenditure (Expenditure on staff, Need for additional finance, Coverage ratio), students (No. of students in 1st cycle/total ratio, No. of international students/total ratio), Employability and supply of qualified workforce (Total number of lecturers and researchers/total students ratio), Volume of service provision activities (Declared value of service provision/total own income), R\&D institutions/centers (No. of publications ISI [Institute for Scientific Information], currently WoS [Web of Science]/total No. of publications ratio), Social and cultural environment (Rate of scientific, cultural, social and sporting events) and students' Expenditure (Students' annual cost of living/national minimum salary ratio).

The outputs and respective relevant key indicators may be: Teaching (No. of graduates/total No. of Diplomas ratio, Rate of schooling in higher education), R\&D (No. of patents registered, No. of publications ISI[WoS]/total ratio, PhDs in higher education, No. of enterprises in R\&D activities/total R\&D enterprises), Social, civic and environmental (Total number of social action grants awarded/total grants requested ratio, No. of accesses to broadband internet service at a fixed location/total accesses ratio, No. of staff working in artistic, performance, sporting and recreational activities/total staff ratio), Economic (Rate of enterprise birth, Turnover of enterprises in high and medium-high technology sectors/total turnover in these enterprises ratio, Enterprises' turnover/total turnover ratio, Enterprises' total investment rate).

\section{Discussion}

HEIs are considered to be key vehicles for the achievement of the objectives set by the EU for Horizon 2020 Community Research \& Innovation Framework Program, as they are increasingly seen as catalysts for development, with a very substantial contribution as providers of education and $R \& D$, and as promoters in the development of regional, social, cultural and human capital economies.

Studies from the EU state that investing in setting up a HEI in a region does not necessarily mean that its outputs are related to its development. Therefore, HEIs and their stakeholders must be guided by demanding criteria of quality, equity and efficiency.

HEIs are expected to add value to the region by offering: (i) tangible benefits such as population growth resulting from attracting people to the institution, job opportunities, strengthening local GDP and setting up start-ups and spin-offs; and (ii) flexible and innovative responses that contribute to the region's transformation and economic growth.

Regarding the input indicators analyzed, we verified that, in recent years, there has been an increase in the number of Students enrolled in higher education, with the vast majority enrolled in Public education and University education. Staff in R\&D Activities has seen a significant increase over the past few years and are found mainly in HEIs and Enterprises, such as Expenditure in R\&D.

As for the output indicators, the number of Higher education graduates has also increased in recent years, most with the level of Graduate. The Employed population with tertiary education as a level of education has also increased consistently. At the same time, there has been an increase in the number of enterprises, GDP and Apparent labor productivity in Portugal, as well as Enterprises with technological innovation activities. However, the Patent of inventions registered has decreased.

It can also be added that, according to SYP [Statistical Yearbook of Portugal] (2018), the expenditure on R\&D stood at $1.3 \%$ of GDP in 2017, and the number of personnel involved in R\&D activities in the total labour force was $10.5 \%$. The national expenditure on R\&D amounted to $€ 2,585$ million in 2017 , i.e., $8.2 \%$ more than in the previous year, keeping the upward trend. It continued to be mostly accounted for by Enterprises and Tertiary education sectors.

With regard to enterprise innovation, data covering the period 2014-2016 show that $66.8 \%$ of the enterprises under analysis developed specific activities to implement a new or significantly improved product, process, organizational or marketing method. Of these, $23.2 \%$ did so using public financial support, and $16.0 \%$ integrated into projects with 
other partners (enterprises or other organizations). The sales of new products resulting from innovation activities accounted for $14.8 \%$ of the turnover of the enterprises under analysis (SYP, 2018).

In 2016-2018 period, in Portugal, 32.4\% of enterprises had innovation activities, 23\% introduced product innovation (goods or services), 28\% introduced process innovation and 31.4\% introduced product innovation and/or process innovation. $7.5 \%$ of the enterprises had in-house (R\&D) activities and $4 \%$ of the enterprises contracted-out R\&D to other enterprises or to public or private research organizations. By economic activity, the sector with the highest percentage of innovative enterprises was Information and communication (57.4\%), followed by the sectors of Financial and insurance activities (45.4\%), Industry (37.8\%) and Energy and water (37.2\%). Regarding process innovation, 20.4\% of enterprises introduced methods of organizing work responsibility, decision-making or human resource management, $17.8 \%$ of the enterprises introduced methods for information processing or communication and $17.5 \%$ introduced methods for producing goods or providing services (NIS, 2020).

In should also be noted that, according to recent data from the EU (2020) in the European Innovation Scoreboard 2020, the Portuguese scientific and innovation system had a performance above the EU average, leading the country into the Strong Innovators UE State Members group. In fact, Portugal is, according to that Scoreboard, the UE leader in the area of innovation in SMEs.

Taking into account all indicators, which are mostly positive in recent years in Portugal, we infer that they will have substantial repercussions on the population's well-being and on improving their quality of life, as evidenced by the report on Welfare Index Indicator (WII) (2018).

This report presents the Welfare Index of the Portuguese population, which evolved positively between 2004 and 2011, with an annual growth of $3.8 \%$ in 2017. The Welfare Index portrays the evolution of the population's well-being using two indices: Material living conditions and Quality of life. Between 2004 and 2013, these two indices evolved in opposite directions, with the first - Material living conditions - showing a decreasing trend and the second - Quality of life - showing an increasing trend. From 2013 onwards, both indices started to evolve in the same direction: improving welfare.

Of the ten domains that make up the WII (2018), Education and Civic Participation and Governance showed the most favourable evolution. This reinforces the importance and weight that higher education can have in the quality of life. Conversely, the Labour and Remuneration and Economic Vulnerability domains are those whose evolution has been most unfavourable, although they have been recovering since 2013.

\section{Conclusion}

Despite the increase in R\&D expenditure and the number of R\&D individuals in the total working population, with HEIs executing about $40 \%$ of their national R\&D investment, their outputs are lower than desired, namely the economic ones. However, not limited to this component, there has been a progressive and sustained increase in the well-being of the Portuguese population and their quality of life in recent years.

In this sense, HEIs'practices and their responsibility in terms of increasing the qualification of the population in higher education and innovation and knowledge transfer to enterprises and society, with the consequent contribution of enterprises, have certainly contributed for this increase.

After the current Covid-19 pandemic, the challenge for HEIs will be higher, with the consequent influence on the country and world economy and education systems. The pandemic, among other changes, forced HEIs to move from face-to-face to distance learning in a short period of time, assuming the integration of digital technologies and the need for more training in this area, which are critical in this context. This, together with other aspects, especially the economic and the financing dimensions, will certainly bring new contributions that will positively or negatively influence HEIs and the populations' quality of life.

We cannot anticipate all the consequences at this point, but the number of Students enrolled in higher education may likely decrease or experience slow growth, as well as Staff and Expenditure in R\&D Activities. Consequently, in the future, we may have less Higher education graduates and Employed population with tertiary education. It is also likely that the Number of companies and GDP will decrease with the economic crisis already installed in Portugal, alongside the disinvestment in Technological innovation activities.

With the development of this research project, U-Value, about the impact of HEIs on the quality of life of regions, we intend to take an innovative approach in the study of the impact that HEIs have on the quality of life of the regions where they operate, as well as their efficiency in transforming public funds, own funds and different types of human, social and organizational capital into outputs that influence the QoL of the populations and the sustainability of their regions. 


\section{Acknowledgements}

This work was supported by the FCT - Fundação para a Ciência e a Tecnologia [Foundation for Science and Technology], within the scope of the research activities developed in the project PTDC/EGE-OGE/29926/2017.

\section{References}

Berger, M. C., \& Black, D. A. (1993). The Long Run Economic Impact of Kentucky Public Institutions of Higher Education. Lexington, KY: University of Kentucky Center for Business and Economic Research.

Drucker, J. (2016). Reconsidering the Regional Economic Development Impacts of Higher Education Institutions in the United States. Regional Studies, 50(7), 1185-1202. https://doi.org/10.1080/00343404.2014.986083

European Commission /EACEA/Eurydice (2018). The European Higher Education Area in 2018: Bologna Process Implementation Report. Luxembourg: Publications Office of the European Union. Retrieved from https://eacea.ec.europa.eu/national-policies/eurydice/content/european-higher-education-area-2018-bolognaprocess-implementation-report_en

European Union (2020). European Innovation Scoreboard 2020 Report. Retrieved from https:/ec.europa.eu/growth/industry/policy/innovation/scoreboards_en

Kelly, U., McNicoll, I., \& McLellan, D. (2006). The economic impact of UK higher education institutions. Universities UK (Vol. March), London. Retrieved from http://strathprints.strath.ac.uk/3109

Leitão, J., Alves, H., \& Pereira, D. (2016). Open Innovative Governance, Municipalities’ Transparency and Citizens’ Quality of Life: Are They a Perfectly Matched Trilogy? In J. Leitão, H. Alves (eds.), Entrepreneurial and Innovative Practices in Public Institutions, Applying Quality of Life Research, Chapter 9. Springer International Publishing Switzerland. https://doi.org/10.1007/978-3-319-32091-5_9

Leitão, J., Ferreira, J. M., \& Azevedo, S. G. (2008). Dimensões competitivas de Portugal [Competitive dimensions of Portugal]. Lisboa: Centro Atlântico Lda.

NIS [National Institute of Statistics; Directorate-General for Education and Science Statistics] (2020) Direção-Geral de Estatísticas da Educação e Ciência; Instituto Nacional de Estatística (2020). Inquérito Comunitário à Inovação [Community Innovation Survey]: 2016-2018. Lisboa: INE. Retrieved from https://www.ine.pt/xurl/pub/452685463

Pedro, E. M., Leitão, J., \& Alves, H. (2020). Bridging Intellectual Capital, Sustainable Development and Quality of Life in Higher Education Institutions. Sustainability, 12(2), 479. https://doi.org/10.3390/su12020479

Pedro, E. M., Leitão, J. \& Alves, H. (2019). The intellectual capital of higher education institutions: Operationalizing measurement through a strategic prospective lens. Journal of Intellectual Capital, 20(3), 355-381. https://doi.org/10.1108/JIC-07-2018-0117

Pedro, E. M., Leitão, J., \& Alves, H. (2018). Capital Intelectual das IES e performance das regiões de influência: Uma abordagem multidimensional e multinomial [Intellectual Capital of HEIs and performance of regions of influence: A multidimensional and multinomial approach]. In 25th Congress APDR - Circular Economy, Urban Metabolism and Regional Development: Challenges for a Sustainable Future, Universidade Nova de Lisboa, Portugal.

SYP [Statistical Yearbook of Portugal] Anuário Estatístico de Portugal (2018), Lisboa: INE. Retrieved from https://www.ine.pt/xportal/xmain?xpid=INE\&xpgid=ine_publicacoes\&PUBLICACOESpub_boui=381689773\& PUBLICACOESmodo $=2$

WII [Welfare Index] Índice de Bem-estar 2004-2017 (2018), Lisboa: INE. Retrieved from https://www.ine.pt/xportal/xmain?xpid=INE\&xpgid=ine destaques\&DESTAQUESdest boui=315227706\&DE STAQUESmodo=2

Winters, J. V. (2011). Human Capital, Higher Education Institutions, and Quality of Life. Munich Personal RePEc Archive. Retrieved from https://mpra.ub.uni-muenchen.de/28484/

\section{Notes}

Note 1. PORDATA [Contemporary Portugal Database], Base de Dados de Portugal Contemporâneo, https://www.pordata.pt

Note 2. NIS [National Institute of Statistics], Instituto Nacional de Estatística, https://www.ine.pt

Note 3. European Commission, EACEA National Policies Platform, Eurydice Reports, 
https:/eacea.ec.europa.eu/national-policies/eurydice/national-description_en

Note 4. EU28 - Economic and political partnership that today encompasses 28 democratic European countries, also included the United Kingdom.

\section{Copyrights}

Copyright for this article is retained by the author(s), with first publication rights granted to the journal.

This is an open-access article distributed under the terms and conditions of the Creative Commons Attribution license (http://creativecommons.org/licenses/by/4.0/). 